\title{
HIPODERMÓCLISE: REVISÃO SISTEMÁTICA DA LITERATURA
}

\author{
HYPODERMOCLYSIS: SYSTEMATIC REVIEW OF LITERATURE
}

\section{Franciele Karoline Gonçalves Vidal ${ }^{a^{*}}$, Gleidson Brandão Oselame ${ }^{b^{*}}$, Eduardo Borba Neves $^{\mathrm{c}^{*}}$, Elia Machado de Oliveira ${ }^{\mathrm{d}^{*}}$}

\author{
afrancielekaroll1303@gmail.com, bgoselame@ics.curitiba.pr.gov.br, cborbaneves@gmail.com, delia561@hotmail.com \\ *Centro Universitário Campos de Andrade - Curitiba, Paraná (PR), Brasil
}

Data de recebimento do artigo: 23/09/2014 Data de aceite do artigo: 21/01/2015

\section{RESUMO}

Introdução: A Terapia Subcutânea, também chamada de Hipodermóclise, ainda é pouco discutida e utilizada. Essa técnica consiste na administração de soluçôes na hipoderme, camada mais profunda da pele, cuja vascularização é similar à que se observa nos músculos. Objetivo: Analisar a produção científica indexada nos periódicos nacionais relacionados ao uso da terapia subcutânea na assistência de Enfermagem. Materiais e Métodos: Optou-se pela revisão sistemática de caráter exploratório com abordagem qualitativa. Realizou-se a busca de estudos em periódicos nacionais publicados nos últimos seis anos, na base de dados da Literatura Latino-Americana em Ciências de Saúde (LILACS) e na Scientific Eletronic Library Online (SciELO). Como os dados sobre o assunto são escassos, utilizou-se o buscador Google acadêmico para incluir publicaçóes do Instituto Nacional do Câncer (INCA). Adotaram-se os termos "hipodermóclise", "terapia subcutânea" e "cuidados paliativos". Resultados: Os estudos analisados resultaram nos seguintes agrupamentos: indicações e contraindicaçôes; vantagens e desvantagens; locais indicados para punção; medicamentos e fluidos utilizados; e a execução da técnica para a punção. Evidenciou-se que a Terapia Subcutânea é um recurso importante para os pacientes em cuidado paliativo. Ela pode contribuir para promoção da qualidade de vida desses doentes. Os riscos são mínimos, os efeitos colaterais são raros, reversíveis e de pouca importância clínica; as vantagens desta via superam suas possíveis desvantagens. Conclusóes: A técnica facilita a alta hospitalar do paciente, favorecendo o cuidado no domicílio, é de fácil aplicação e manipulação e possui baixos custos. No entanto, são necessárias pesquisas para consolidar o uso desse procedimento no Brasil, considerando que há carência de estudos nessa área.

Palavras-chave: Hipodermóclise; Terapia Subcutânea; Cuidados paliativos.

\section{ABSTRACT}

Introduction: Subcutaneous therapy, also called hypodermoclysis, is still little discussed and used. This technique consists in the administration of solutions in the subcutis, the deepest layer of the skin, which vascularization is similar to the one observed in muscles. Objective: Analyze the scientific production indexed in national journals related to the use of subcutaneous therapy in nursing care. Materials and Methods: Systematic review and exploratory qualitative approach. We conducted a search for studies published in national journals in the past six years in the database of Latin American Literature on Health Sciences (LILACS) and Scientific Electronic Library Online (SciELO). Since data on the subject are scarce, we used the Google search engine for scholarly publications, including the National Cancer Institute (INCA). The terms "hypodermoclysis", "subcutaneous therapy" and "palliative care” were adopted. Results: The analyzed studies resulted in the following groupings: indications and contraindications; advantages and disadvantages; indicated locations to puncture; medicinal fluid used; and the implementation of this technique for puncturing. It was evident that subcutaneous therapy is an important resource for patients in palliative care. It can contribute to enhancing the quality of life of these patients. The risks are minimal, side effects are rare, reversible and of small clinical significance; The advantages of this technique exceeds its possible drawbacks. Conclusions: The technique facilitates the discharge of the patient, favoring homecare, it is easy to apply and to manipulate, and implies lower costs. However, the research is needed to consolidate the use of this technique in Brazil, considering that there is a lack of studies in this area.

Keywords: Hypodermoclysis; subcutaneous therapy; palliative care. 


\section{Introdução}

Os novos hábitos de vida têm colaborado para o aumento do número de pessoas com doenças crônicas e degenerativas, que em seu percurso levam os pacientes a necessitarem de cuidados paliativos. Consequentemente, nesses casos, são aspectos prioritários à estabilização, adaptação e manutenção da qualidade de vida, por meio de alternativas para manter o melhor estado de saúde possível $^{1}$.

Em conceito definido pela Organização Mundial de Saúde (OMS), os cuidados paliativos consistem na assistência promovida por uma equipe multidisciplinar, que objetiva a melhoria da qualidade de vida do paciente e de seus familiares, diante de uma doença que ameace a vida ${ }^{2}$. Esse cuidado se dá por meio da prevenção e do alívio do sofrimento, da identificação precoce, da avaliação impecável e do tratamento de dor e demais sintomas físicos, sociais, psicológicos e espirituais. $\mathrm{O}$ cuidado paliativo deve promover o conforto e o bem-estar do paciente, e não apenas sustentar a vida, de modo que o paciente participe das decisóes em relação aos tratamentos que recebe ${ }^{2}$.

A expectativa de vida de pacientes com doenças crônicas têm aumentado, e os cuidados paliativos passaram a ter um papel importante na área da saúde. Nesse grupo de pacientes, a via de utilização deve ser de fácil acesso, de eficácia demonstrada, pouco agressiva, com poucos efeitos secundários e deve ser confortável para o doente. Tudo isso torna a terapia subcutânea uma boa escolha. Dentre as medicaçóes que podem auxiliar o cuidado desses pacientes, estão os antieméticos, sedativos, corticoides, antineoplásicos, antibióticos, entre outros ${ }^{3}$.

O desenvolvimento terapêutico para os cuidados paliativos tem apresentado novas opçóes técnicas na administração de medicamentos e fluidos. A Terapia Subcutânea está entre eles, também chamada de Hipodermóclise, ainda é pouco discutida e utilizada ${ }^{4}$. Essa técnica consiste na administração de soluçóes na hipoderme, camada mais profunda da pele, cuja vascularização é similar à que se observa nos músculos 5 .

Segundo Takaki e Klein ${ }^{6}$ a Terapia Subcutânea surgiu no início do século XX, utilizada em pacientes pediátricos, sendo abandonada em meados do século passado. O autor destaca como razóes que a levaram ao desuso efeitos adversos graves, decorrentes de sua prática inadequada, choque hipovolêmico e/ou administração de solutos hipertônicos, como soluçôes glicosadas a $50 \%$. Para Azevedo et al. 7 , os motivos foram decorrentes da facilidade de aplicação de infusóes pela via intravenosa e tecido muscular.

Para Viegas ${ }^{8}$, a referida via tem suas vantagens, benefícios, indicações e possíveis complicações, podendo contribuir para a promoção da qualidade de vida dos doentes. Existe a necessidade de aprofundar o conhecimento sobre a utilização desse procedimento, justificado pela importância do controle sintomático como um componente essencial no cuidado à pessoa em fim de vida. Para Lopes et al , as imensas vantagens da Terapia Subcutânea superam as suas possíveis desvantagens. Justino et al. ${ }^{4}$ destacam a comodidade para o paciente/ família, a simplicidade para inserção do cateter periférico, a facilidade na administração e manutenção da via por longo período, que, por fim, trazem maior conforto ao paciente.

No estudo realizado por Takaki e Klein ${ }^{6}$, os autores concluem que são necessárias pesquisas em larga escala para consolidar o uso da Terapia Subcutânea no Brasil, considerando que há uma carência de estudos, de divulgação e de utilização segura do método. Para o autor, o enfermeiro desconhece o assunto devido à falta de discussão sobre o tema nas escolas. Assim, considerando a relevância dessa temática, justifica-se que o conhecimento dos enfermeiros sobre o assunto faz-se necessário, pois lhes permite refletir sobre a importância de seu papel ao utilizar esse método como recurso terapêutico. Ainda para os mesmos autores, o conhecimento teórico e prático sobre a Terapia Subcutânea pelo enfermeiro pode minimizar traumas mecânicos e tissulares, promover conforto, diminuir o estresse e dor por punçóes repetidas e sem êxito para a infusão de fluidos e medicamentos, além de minimizar consideravelmente o risco de infecção. É preciso considerar que a administração de medicamentos é uma das funçôes assistenciais exercidas, na maioria das vezes, pela equipe de enfermagem. Para Viegas ${ }^{8}$, esta deverá ser divulgada pelos profissionais de saúde, que na sua maioria a desconhecem. Takaki e Klein ${ }^{6}$ concluem em seu estudo que a hipodermóclise pode ser utilizada fora do âmbito dos cuidados paliativos, e o enfermeiro deve possuir uma visão holística, prestando uma assistência mais humanizada.

Dessa forma, o objetivo primário deste estudo foi analisar a produção científica indexada nos periódicos nacionais relacionados ao uso da Terapia Subcutânea na assistência de enfermagem, descrever especificamente as indicaçôes e contraindicações, vantagens e desvantagens, locais indicados para punção, medicamentos e fluidos utilizados e a execução da técnica para a punção.

\section{Metodologia}

Optou-se pela revisão sistemática de caráter exploratório, com abordagem qualitativa. Esse tipo de pesquisa objetiva desvendar, recolher e analisar as principais contribuiçôes teóricas sobre um determinado fato, assunto ou ideia ${ }^{10}$. 
Realizou-se a busca de estudos em periódicos nacionais publicados entre os anos 2009 e 2014, na base de dados da Literatura Latino-Americana em Ciências de Saúde (LILACS), e na Scientific Electronic Library Online (SciELO). Como os dados sobre o assunto são escassos, utilizou-se o buscador Google acadêmico para acessar publicaçóes do Instituto Nacional do Câncer (INCA). Foram utilizados os seguintes Descritores em Ciências da Saúde (DECS, 2014) para a busca: "hipodermóclise", "terapia subcutânea" e "cuidados paliativos". O recorte temporal da pesquisa é justificado por possibilitar o acesso a dados atuais.

Após a seleção primária dos artigos, foram analisados os títulos e resumos, levando-se em conta os critérios de inclusão: artigos, teses e dissertaçôes, escritos em português e gratuitamente online, publicados nos últimos seis anos (entre os anos de 2009 e 2014); indexados nos bancos de dados selecionados. Nos casos em que apenas o resumo do artigo estava disponível e retratava com clareza o conteúdo do estudo atendendo o propósito da revisão, eles foram incluídos. Contudo, alguns artigos não foram incluídos, devido à duplicidade encontrada nas diferentes bases consultadas. Dessa forma, na última fase de seleção, em que foi realizada a leitura integral de todos os artigos, e aplicados todos os critérios de inclusão e exclusão anteriormente referidos, a amostra final foi constituída por onze artigos completos e seis resumos.

Os artigos, após a sua seleção, receberam leitura exploratória, com a finalidade de identificar a validade do documento para a pesquisa; em seguida, foi avaliado se o material possuía valor para a pesquisa; posteriormente, foi realizada uma leitura analítica para organizar e resumir as informaçóes sobre o objeto de estudo para, posteriormente, receberem uma leitura de característica interpretativa, para relacionar as afirmaçóes dos autores com o problema proposto.

Em seguida, o material selecionado foi analisado e agrupado em unidades temáticas, de acordo com a abordagem dos autores dos manuscritos, para posteriormente serem discutidos com a literatura atual sobre o assunto. A Figura 1 demonstra as etapas da revisão dos estudos.

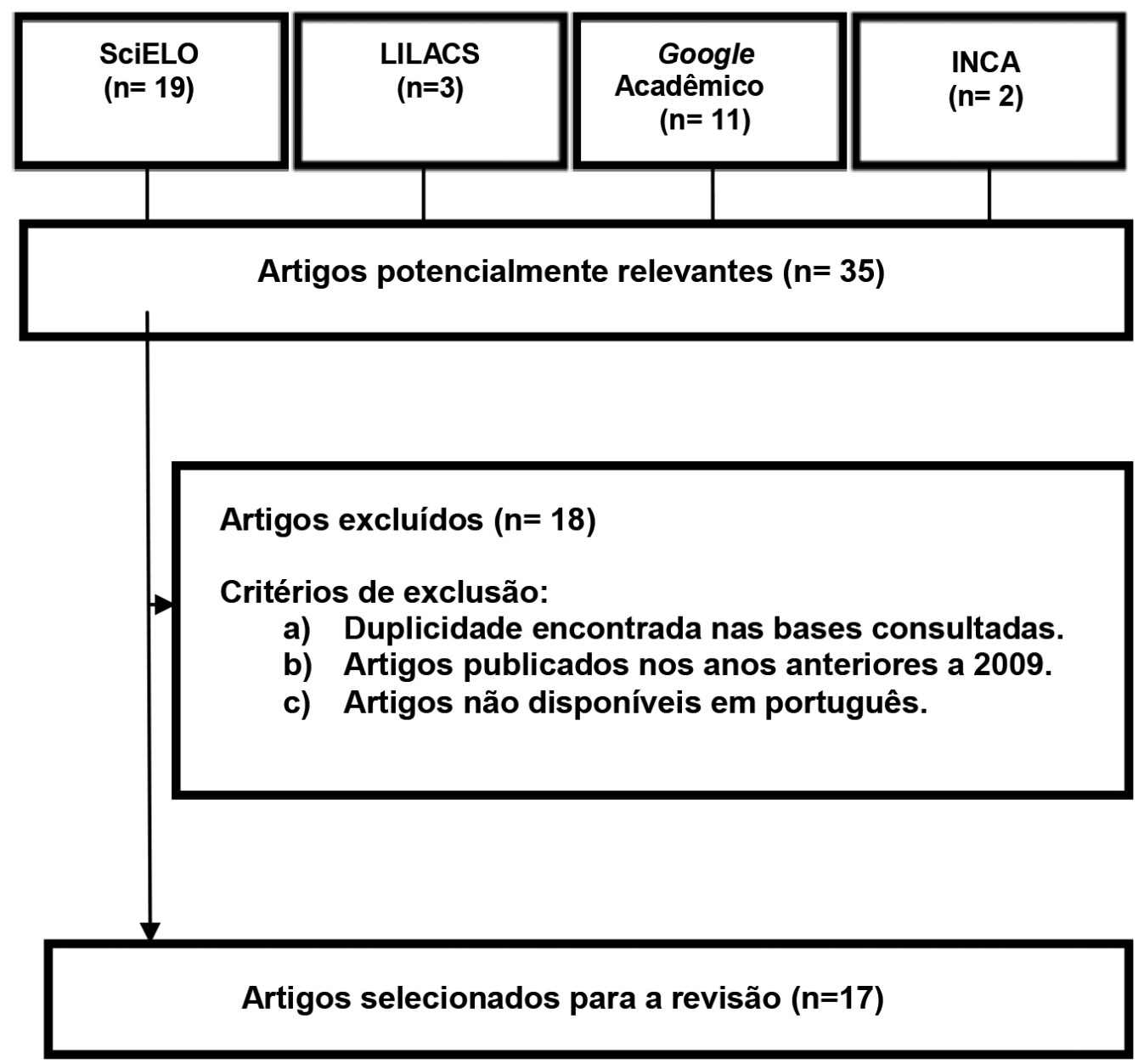

Figura 1: Fluxograma do processo de seleção dos estudos. 


\section{Resultados}

Os estudos analisados resultaram os seguintes agrupamentos: a via subcutânea; vantagens e desvantagens relacionadas ao uso da Terapia Subcutânea; indicaçóes e contraindicaçóes para o uso da Terapia Subcutânea; técnica para punção da hipodermóclise (locais indicados para punção e material utilizado); medicamentos permitidos e proibidos; e volume de fluidos suportados pela via subcutânea.

\section{Discussão}

\section{A via subcutânea}

O tecido subcutâneo, por ser dotado de inúmeros capilares sanguíneos, é uma via favorável à administração de fluidos e/ou fármacos, pois estes serão absorvidos e transportados pelos capilares à macrocirculação. Os medicamentos administrados pela via subcutânea têm ação farmacocinética semelhante à via intramuscular, atingindo, no entanto, uma concentração sérica menor, mas com tempo de ação prolongada. Com isso, evita-se o clearance pré-sistêmico pelo fígado, originando uma concentração sérica estável do medicamento, evitando efeitos colaterais indesejáveis por consequência de picos plasmáticos $^{8}$.

No estudo de Pontalti et al. ${ }^{5}$, ressalta-se que a utilizaçáo da via subcutânea elimina o primeiro passo do metabolismo hepático, acarretando alta biodisponibilidade da droga (90\%). As características físico-químicas das substâncias, condições cardiovasculares, presença de vasoconstrição cutânea e local de aplicação são fatores que podem influenciar na absorção.

Conforme descrito por Lopes et al. ${ }^{9}$, existem restrições para o uso de alguns fármacos por essa via por causa de suas características, necessitando ser hidrossolúveis e bem toleráveis no tecido conjuntivo e adiposo para evitar complicaçóes, além de limitações legais de fármacos para utilização por essa via.

\section{Vantagens e desvantagens relacionadas ao uso da Terapia Subcutânea}

Com a impossibilidade do uso via oral, ou quando surge a necessidade do uso de outra via que não seja esta, a via subcutânea é considerada a primeira opção, tanto para administração de fármacos como para hidratação. Essa técnica de punção promove conforto, comodidade, autonomia, satisfação, alívio do estresse e esperança ao paciente, promovendo melhora na sua qualidade de vida?

O mesmo autor destaca que a via subcutânea é bem tolerada pelos doentes. Se comparada ao acesso venoso, tem menor taxa de complicaçóes infecciosas e é de fácil aplicação e manipulação, implicando menores custos.

Pontalti et al. ${ }^{5}$ mencionam as seguintes vantagens da referida via: menos dolorosa, complicaçóes raras, boa aceitação, efetividade, favorecimento da funcionalidade do doente, baixo índice de infecção e redução da flutuação das concentraçôes plasmáticas de opioides. Lopes et al. ${ }^{9}$ acrescentam a possibilidade de utilizar a maioria dos fármacos necessários em cuidados paliativos.

Evidencia-se que o manuseio simples do dispositivo facilita a alta hospitalar do paciente, apresentando risco mínimo de desconforto ou complicação local, e traz menor grau de limitação pelas opçôes diferenciadas dos sítios de punção (comumente distante das articulaçôes). Também apresenta risco mínimo de complicaçôes sistêmicas, como a hiper-hidratação e sobrecarga cardíaca, podendo ser monitorado ao longo do período de infusão ${ }^{11}$.

Para Takaki e Klein ${ }^{6}$, é de fácil manejo tanto na conservação quanto na manipulação, favorecendo o cuidado no domicílio, principalmente por pessoas que não são da área da saúde. Ainda elimina a necessidade de injeçóes frequentes, o que garante mais conforto ao paciente. Outra vantagem é que a infusão pode ser interrompida a qualquer hora, sem risco de trombose. Considerando os riscos, que são mínimos, os efeitos colaterais são raros, reversíveis e de pouca importância clínica, desse modo, essa via pode ser considerada segura. Além da hidratação, a hipodermóclise propicia a infusão de medicamentos, tais como analgésicos, antibióticos e agentes antineoplásicos.

Esta via pode ser utilizada de forma contínua ou intermitente, em bolus ou infusão contínua. A administração de fluidos e de fármacos por meio dela reduz o período de latência do medicamento (tempo para iniciar a ação), quando comparada à via oral. Pode ser implementada onde quer que o paciente se encontre. É a melhor via para administração de opioides, de forma segura, eficaz e com poucos efeitos adversos 5 . Relativamente, as principais indicações apresentadas por Viegas ${ }^{8}$ sáo: o controle da dor, dos vômitos e da sedação.

Para Viegas ${ }^{8}$, é uma via menos traumática, menos invasiva, de técnica simples e de fácil punção, apresenta menos efeitos secundários que a via endovenosa e mantém a autonomia do doente. Quanto aos benefícios, pode ser utilizada simultaneamente com comprimidos orais, de modo que o doente usufrua todos os benefícios de uma via parenteral. A perfusão pode ser interrompida sem haver o risco de o acesso ficar disfuncional. $\mathrm{O}$ autor assegura que a hipodermóclise é a forma mais fácil e conveniente para promover a hidratação, principalmente em idosos, pois a desidratação destes leva à morbidade e consequente mortalidade. 
No que tange às desvantagens, Viegas ${ }^{8}$ aponta as que se relacionam ao procedimento, à introdução de pequenos volumes e à limitação na administração de eletrólitos e alguns fármacos. Ele associa as complicaçóes que podem ocorrer com o uso dessa técnica como desvantagem, entre elas: eritema, edema local (por excesso de líquidos), hemorragia ligeira e hematoma local, prurido, abscessos, inflamação, dor e infecção local. Não é indicada a administração de mais de três fármacos no mesmo acesso. Para Takaki e Klein ${ }^{6}$, pode ocorrer inflamação ou infecção no local da punção, gerando necessidade de troca do sítio de punção.

Pontalti et al. ${ }^{5}$ afirmam que os efeitos adversos da administração por essa via são raros e evitáveis. Como reaçôes locais, podem surgir vermelhidão, endurecimento da pele e extravasamento. Dentre as raras complicações documentadas, relacionadas principalmente pela seleção do fármaco, estão o granuloma e a celulite. Os autores afirmam que não há desenvolvimento de fármacos para o uso da via subcutânea, especificamente em substituição ao uso da via oral.

Ressaltam D'Aquino e Souza ${ }^{11}$ que a hipodermóclise náo pode ser usada em pacientes com trombocitopenia ou problemas de coagulação. Afirmam não ser via de escolha para grandes volumes, pela possibilidade de apresentar sinais flogísticos.

Azevedo et al. ${ }^{7}$ constataram a inexistência do uso de antibióticos por via subcutânea em pacientes sob cuidados paliativos, tornando-se uma desvantagem para tais pacientes, que muitas vezes necessitam do uso de antibióticos para a manutenção da sua qualidade de vida.

Existe ainda a limitaçáo quanto à necessidade de ajuste rápido de doses, pois a absorção pelo tecido subcutâneo é mais lenta do que pela via intravenosa para a maioria dos medicamentos. Essa via apresenta limitaçôes nas situaçôes em que se deseja uma velocidade de infusão rápida e reposição com alto volume de fluidos ${ }^{12}$.

\section{Indicações e contraindicações para o uso da Terapia Subcutânea}

A via subcutânea é indicada para pacientes com perda ou impraticabilidade da via oral, surgindo a necessidade de escolha de uma nova via para administração de medicamentos ou para hidratação. É benéfica também em casos de desidrataçáa ligeira, associada a sintomas desconfortantes, ou de causas reversíveis. Salienta-se seu uso como positivo em condiçóes de emergência, no alívio ou na supressão de confusão e agitação psicomotora, no aumento da excreção renal, na hidratação da pele como complemento preventivo da formação de úlceras de pressão, e ainda na prevenção da obstipação?.

Ainda para o mesmo autor, a hipodermóclise deve ser prática de primeira escolha, perante casos não emergentes em doentes idosos e/ou terminais. Pacientes com doença crônica de evolução prolongada, principalmente em fim de vida, preferem permanecer no domicílio, preservando assim a vida familiar, facilidade esta que pode ser proporcionada pela Terapia Subcutânea.

Conforme Viegas ${ }^{8}$, a principal indicação para o uso dessa via é a agonia, ou seja, quando o paciente está muito perto da morte; o controle da dor, dos vômitos e da sedação, necessidade de efeito rápido da medicação, disfagia, obstruçáo intestinal, confusão, doses elevadas por via oral, necessidade de sedação terminal, intolerância a opioides por via oral, marcada redução da absorção gastrointestinal, prostração extrema e inconsciência.

Pontalti et al. ${ }^{5}$ afirmam que é amplamente indicada em casos de desidrataçáo moderada, nos quais tanto a rede venosa quanto a ingestão de líquidos por via oral encontram-se impraticáveis, e ainda em casos de intolerância gástrica e diarreia. É recomendada a realização de um rodízio de locais para minimizar o dano ao tecido. É uma técnica segura e efetiva para oferecer fluidos e analgesia adequada em pacientes idosos com doenças crônicas, degenerativas ou câncer.

A hipodermóclise pode ser útil para pacientes que se alimentam por via oral em menores quantidades, e que não apresentam cateter entérico, dispensando, nesse caso, a venóclise. Para os autores, as indicaçóes mais frequentes para a hipodermóclise são: pacientes que necessitam de analgesia com incapacidade de ingerir por via oral e reposição de eletrólitos, pacientes com descompensação, além da administração de antibióticos em indivíduos que não apresentam possibilidade de acesso venoso seguro e confortável ${ }^{6}$.

Para Justino et al. ${ }^{4}$, a hipodermóclise pode ser considerada uma via de escolha tanto em ambiente hospitalar quanto domiciliar, para pacientes em que a via intravenosa encontra-se debilitada devido às terapêuticas medicamentosas, principalmente com agentes quimioterápicos. Dessa forma, essa técnica pode ser considerada uma via de escolha para a reposição de fluidos, eletrólitos e alguns tipos de medicamentos. É também via alternativa em casos de pacientes portadores de câncer em estágio avançado, que apresentam acesso venoso prejudicado, devido às condiçôes clínicas (caquexia, desidratação) e à terapia com agentes esclerosantes ${ }^{11}$, além de ser uma opção no controle da dor, na administração terapêutica, ou para hidratação em pacientes com doenças oncológicas, doenças neurológicas degenerativas, ou Síndrome da Imunodeficiência Adquirida ${ }^{13-14}$.

Takaki e Klein ${ }^{6}$ destacam as principais indicações para o uso da hipodermóclise: impossibilidade de ingestão por via oral; náuseas; vômitos incoercíveis; obstrução do trato gastrintestinal por neoplasia; impossibilidade de acesso venoso; pacientes com difícil acesso venoso e que tenham seu sofrimento aumentado pelas 
constantes tentativas de punçáo, ou casos de flebite, trombose venosa e sinais flogísticos; possibilidade de permanência do paciente em domicílio, por ser um método seguro, sem graves complicaçóes e de fácil manipulação.

No que tange às contraindicaçôes, Takaki e Klein ${ }^{6}$ ressaltam que a hipodermóclise não pode substituir a via intravenosa em algumas situaçôes, por exemplo, para tratar desidratação severa, para nutrição parenteral ou para utilizar cateter nasogástrico nos tratamentos de desnutrição.

Para Lopes et al. ${ }^{9}$, as contraindicaçóes à colocação de acesso subcutâneo podem estar relacionadas a: edemas; hemorragia ou distúrbio da coagulação; comprometimento ou lesão tecidual; insuficiência cardíaca; desidratação grave; infecção; doentes em diálise peritoneal ou ainda a não aceitação do doente ou família. Perante hemorragia severa, essa via torna-se ineficaz, pelo déficit de absorção associado à falha da circulação periférica por perda sanguínea. Viegas ${ }^{8}$ afirma que existem poucas contraindicaçóes para a escolha dessa via, como: anasarca; hemorragia aguda profusa; choque; alteraçóes generalizadas da integridade cutânea; situaçóes em que seja necessária a administração de soro em grandes quantidades e rapidamente; infecção de repetição nos locais de punção; coagulopatias; doentes em hemodiálise; e tecidos perto de cicatrizes operatórias ou em tratamento com radioterapia.

Dessa forma, Pontalti et al. ${ }^{5}$ destacam que, entre as principais contraindicaçóes relativas, incluem-se: edema; insuficiência cardíaca; desidratação grave; distúrbios de coagulação; foco infeccioso próximo ao local da punção; e a não aceitação do paciente ou cuidador e a administração em pacientes com diálise peritoneal. $\mathrm{O}$ autor destaca que se o paciente está recebendo tratamento radioterápico, a área de escolha deve ser diferente da irradiada. Devem-se evitar também os locais com danos de pele, em fase de cicatrização ou edemaciados. Por fim, um dos principais cuidados é não puncionar ao lado de uma mastectomia, ou próximo de um estoma.

\section{Técnica para punção, locais indicados e material utilizado}

Técnica para punção

O enfermeiro deverá: explicar o procedimento ao paciente; escolher o local da infusão; fazer antissepsia e a dobra na pele; introduzir o scalp num ângulo de 30 a $45^{\circ}$ (a agulha deve estar solta no espaço subcutâneo); fixar o scalp com o filme transparente; assegurar que nenhum vaso tenha sido atingido; aplicar o medicamento ou conectar o scalp ao equipo da solução; datar e identificar a fixaçãa ${ }^{11}$. Conforme destaca
Viegas ${ }^{8}$, ao puncionar, deverá fazê-lo de acordo com as linhas da pele, para ser menos doloroso ao doente. Nesse contexto, também deve-se realizar uma prega para estimular os nociceptores e diminuir a dor. Caso, ao puncionar, reflua sangue, o enfermeiro deverá comprimir a zona de punção durante 2 ou 3 minutos e puncionar outro local. A autora explica que o novo local de punçáo deve localizar-se a uma distância mínima de $5 \mathrm{~cm}$ da antiga punção. Nesse sentido, segundo Takaki e Klein ${ }^{6}$, após a antissepsia local com álcool a $70 \%$, deve-se puncionar a pele num ângulo de 45 a $60^{\circ}$ numa prega cutânea, fazer uma rotação de $180^{\circ}$ com o bisel da agulha para baixo, proporcionando melhor difusão e evitando a obstrução da agulha causada pela gordura do tecido subcutâneo. No entanto, é necessário ter uma atenção especial para não puncionar o tecido intradérmico, o que promoveria o extravasamento de líquido.

Locais indicados para punção

Sempre que possível, o doente deverá escolher a regiāo a ser puncionada, com preferência para locais que não interferem nos movimentos do doente. Destacamse alguns locais de punção a utilizar: a região subclavicular (evitando sempre o tecido mamário e zonas adjacentes); região escapular (quando o doente se encontra com agitaçấo e com tendência para arrancar as perfusões, com delírios); região abdominal (considerando uma circunferência em torno do umbigo com cerca de quatro dedos em volta dele); região externa das coxas e regiốes externas dos braços (em último recurso). A região peitoral em homens e a região inframamária em mulheres. Nos doentes com caquexia, o espaço intercostal deverá ser evitado, por risco elevado de pneumotórax. Ressaltase que a região torácica e abdominal são as áreas de maior absorção ${ }^{8}$.

Já Takaki e Klein ${ }^{6}$ destacam que, em casos de incontinência urinária e/ou insuficiência vascular periférica, a face interna da coxa deve ser evitada. Os autores afirmam que o enfermeiro tem a função de avaliar o paciente antes da aplicação, escolhendo o local adequado para a punção, em regióes com a integridade cutânea mantida. Pode-se utilizar a região do flanco; infraclavicular; axilar; face anterior interna ou externa da coxa.

Justino et al. ${ }^{4}$ concluíram, em seu estudo, que os locais indicados para punção subcutânea são: região infraclavicular; região infraescapular; região abdominal (flanco); face anterior, interna ou externa da coxa; região anterior e externa dos braços (deltoide). Os autores destacam essas regióes por suportarem um volume bem acima do tolerado pela técnica tradicional de injeção subcutânea, que, segundo eles, seria de até dois mililitros. Para os autores, na escolha do local da punção, 
deve-se levar em consideração o volume de líquido a ser administrado. Ou seja, é importante que a regiáo escolhida tenha quantidade de tecido subcutâneo para a infusão de maiores volumes, e a regiáo abdominal é uma boa opçáo. Os mesmos autores destacam outras observações importantes: evitar administração direta sobre o local do tumor; em membros com linfedema; em pele previamente irradiada, uma vez que o suprimento sanguíneo pode estar reduzido; em locais com infecção, fissuras ou hematomas e na região abdominal, quando houver presença de ascite.

Para Pontalti et al. ${ }^{5}$, os locais de inserção do cateter por via subcutânea são os mesmos da administração de insulina, ou seja, o abdômen, o tórax superior, a área escapular, as coxas e os braços. Em pacientes acamados, os locais mais adequados são: as coxas; o abdômen; acima da escápula; e na parede anterior ao tórax. Para os autores, os melhores locais para punção são aqueles com maior quantidade de tecido. Dessa forma, indica-se parede torácica anterior; os quadrantes abdominais ( $6 \mathrm{~cm}$ a $8 \mathrm{~cm}$ ao redor do umbigo); as laterais das coxas, aproximadamente $4 \mathrm{~cm}$ acima do joelho e $4 \mathrm{~cm}$ abaixo do trocanter; a área escapular posterior e supraescapular; a face anterior e posterior do músculo deltoide.

Conforme D’Aquino e Souza ${ }^{11}$, pode-se utilizar o espaço intercostal, a área abaixo da regiáo escapular e a região do abdômen. Pacientes preferem essas regióes à área dos braços, pois podem ter os movimentos livres. Ressaltam Arriera et al. ${ }^{3}$ os sítios de punção mais utilizados: região abdominal; tríceps; regióes internas e externas das coxas; regiāo infraclavicular e interescapular; sendo esta adequada em pacientes agitados. A escolha do sítio da punção pode incluir ainda a região deltoide; região anterior do tórax; região escapular; região abdominal; e face lateral da coxa ${ }^{12}$. A Figura 2 ilustra os principais pontos indicados para punção, conforme identificado nesta revisão.
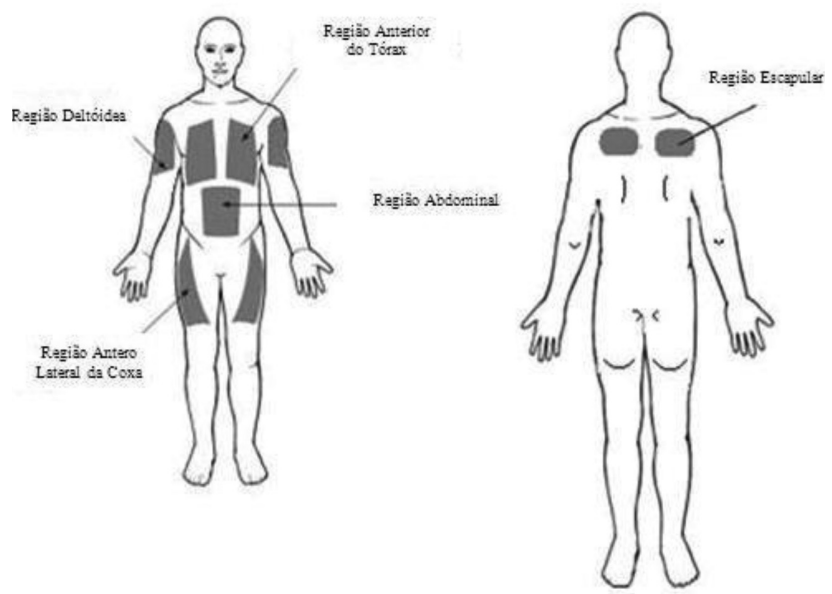

Figura 2: Locais de punção. Adaptado de: Soriano Fernandez et al. ${ }^{15}$

\section{Material utilizado}

No que concerne à eleição do dispositivo a ser utilizado, calibre e tempo de permanência devem ser considerados. Para Pontalti et al. ${ }^{5}$, na punção do acesso subcutâneo, utiliza-se agulha de metal, tipo borboleta, de números 21 ou 23 , inserindo a agulha em tecido subcutâneo, fixado por um curativo transparente, para visualizar a pele circundante. $\mathrm{O}$ uso de dispositivos plásticos, como cateteres 24 ou 22 , também é possível. O tempo de permanência do dispositivo segue o padráo instituído para os acessos venosos em até 96 h. Porém, na prática clínica, junto ao serviço domiciliar, ele impóe quantidade maior de tempo, com média de variância de cinco dias quando a punção é para a administração de somente uma droga. Para os autores, a via subcutânea pode ser utilizada de modo contínuo. Um exemplo é a infusão por meio de bombas que liberam o medicamento em um ritmo de $2 \mathrm{ml} / \mathrm{h}$ ou até $0,5 \mathrm{ml} / \mathrm{h}$ no tecido subcutâneo continuamente.

Para Justino et al. ${ }^{4}$, o dispositivo de escolha é o cateter agulhado, escalpe, com variação no calibre de acordo com a quantidade de tecido subcutâneo do paciente e do volume a ser infundido, são recomendados os calibres 21 ao $27 \mathrm{G}$, sendo este adequado para pacientes pediátricos ou caquéticos. Para os autores, o tempo de permanência, independentemente do cateter utilizado, pode ser de até sete dias, desde que não haja sinal flogístico.

Conforme Viegas ${ }^{8}$, são utilizadas agulhas epicranianas-c Buterffly, calibre entre 21 e $25^{\circ}$. Na administração de fármacos podem permanecer de 5 a 8 dias no mesmo local e, no uso de dispositivo de Teflon, podem chegar a ultrapassar esse número, essas agulhas têm se revelado mais vantajosas às típicas agulhas epicraneanas.

Takaki e Klein ${ }^{6}$ ressaltam o uso de scalp calibre 2527 ou jelco, solução intravenosa, álcool, seringa, esparadrapo, luvas de procedimento e equipamento para administração de fluidos contínuos.

\section{Medicamentos permitidos e proibidos e volume de fluidos suportados pela via subcutânea}

São bem tolerados os medicamentos cujo $\mathrm{pH}$ fica próximo à neutralidade, e que sejam hidrossolúveis. Entre o arsenal medicamentoso, existem alguns remédios que tradicionalmente são utilizados pela via subcutânea. Conforme Pontalti et al., ${ }^{5}$ os fármacos mais utilizados na via subcutânea em cuidados paliativos são os hidrossolúveis, bem toleráveis no tecido conjuntivo e adiposo, apresentando menor risco de efeito acumulativo. 
Segundo D'Aquino e Souza ${ }^{11}$, o medicamento mais usado por essa via é a morfina, porque sua vida média é curta e sua concentração plasmática é alcançada rapidamente. A administraçáo de soluçáo de opioides altamente concentrada no tecido celular subcutâneo por meio de bomba infusora facilita a infusão, mesmo na residência do paciente, trazendo alívio da dor.

No estudo realizado por Justino et al. ${ }^{4}$, o fármaco mais utilizado foi a morfina, prescrito para $15(93,75 \%)$ pacientes, administrada isoladamente, ou em combinação com outras drogas. Nos cinco pacientes em que a hipodermóclise foi utilizada como via para hidratação, as soluções administradas foram fisiológica, glicosada e glicose hipertônica. As as soluçôes melhor toleradas são as isotônicas e hidrossolúveis, por serem menos irritantes e apresentarem menor risco de acumulação; soluçōes muito ácidas ou básicas podem aumentar o risco de precipitação ou irritação. No contexto citado, os autores ressaltam que a soluçáo glicosada a 5\% é isenta de riscos.

Importante ressaltar que, com os avanços científicos nessa área de conhecimento, outros medicamentos têm sido estudados, a fim de terem seu uso padronizado através da via subcutânea ${ }^{16}$. O Quadro 1 apresenta as drogas utilizadas pela via subcutânea.

Quadro 1: Drogas utilizadas pela via subcutânea.

\begin{tabular}{|c|c|c|}
\hline CLASSE & NOME & AÇÃO \\
\hline $\begin{array}{l}\text { Analgésicos } \\
\text { opiáceos }\end{array}$ & $\begin{array}{l}\text { Morfina, fentanil, } \\
\text { tramadol, metado- } \\
\text { na e hidromorfina }\end{array}$ & $\begin{array}{l}\text { Alívio da dor de inten- } \\
\text { sidade moderada, severa } \\
\text { de caráter subagudo, } \\
\text { agudo e crônico }\end{array}$ \\
\hline Antieméticos & $\begin{array}{l}\text { Metroclopramida, } \\
\text { dimenidrina- } \\
\text { to, ciclizina e } \\
\text { ondansetrona }\end{array}$ & $\begin{array}{c}\text { Tratamento de náuseas e } \\
\text { vômitos }\end{array}$ \\
\hline $\begin{array}{c}\text { Análogo } \\
\text { somatostina }\end{array}$ & Octreotide & Antidiarreico \\
\hline sedativos & $\begin{array}{l}\text { Midazolan, } \\
\text { fenobarbital, } \\
\text { clorpromazina }\end{array}$ & $\begin{array}{c}\text { Tratamento de ansiedade } \\
\text { e sedação }\end{array}$ \\
\hline Anti-histamínico & $\begin{array}{c}\text { Prometazina e } \\
\text { hidroxizina }\end{array}$ & $\begin{array}{c}\text { Reações anafiláticas e } \\
\text { alérgicas }\end{array}$ \\
\hline Anticolinérgicos & $\begin{array}{c}\text { Atropina e } \\
\text { escopolamina }\end{array}$ & $\begin{array}{l}\text { Antiespasmódico, } \\
\text { antiarrítmico }\end{array}$ \\
\hline Corticosteroides & Dexametasona & $\begin{array}{l}\text { Anti-inflamatório, } \\
\text { imunossupressor }\end{array}$ \\
\hline Bloqueadores $\mathrm{H} 2$ & $\begin{array}{l}\text { Ranitidina e } \\
\text { famotidina }\end{array}$ & $\begin{array}{c}\text { Tratamento e prevenção } \\
\text { de úlceras duodenal e } \\
\text { gástrica benigna }\end{array}$ \\
\hline Diuréticos & Furosemida & $\begin{array}{c}\text { Hipertensão arterial } \\
\text { leve a moderada, edema } \\
\text { devido a distúrbios } \\
\text { cardíacos, hepáticos e } \\
\text { renais }\end{array}$ \\
\hline
\end{tabular}

continua...
Quadro 1: Continuação.

\begin{tabular}{|c|c|c|}
\hline CLASSE & NOME & AÇÃO \\
\hline Bifosfanatos & Clodronato & $\begin{array}{c}\text { Inibe destruição óssea } \\
\text { progressiva, aliviando as } \\
\text { dores ósseas }\end{array}$ \\
\hline Antibióticos & $\begin{array}{c}\text { Ampicilina, cefepi- } \\
\text { me, ceftazidima, } \\
\text { cefotaxima, ceftria- } \\
\text { xona, tobramicina } \\
\text { e garamicina }\end{array}$ & $\begin{array}{c}\text { Tratamento de infecçóes } \\
\text { no trato urinário, respi- } \\
\text { ratório, digestivo e biliar. } \\
\text { Antibiótico bactericida }\end{array}$ \\
\hline AINH & $\begin{array}{c}\text { Ketorolac } \\
\text { da dor aguda, de intensi- } \\
\text { dade moderada a severa } \\
\text { com propriedades anal- } \\
\text { gésicas, anti-inflamató- } \\
\text { rias e antipiréticas }\end{array}$ \\
\hline Anestésico & Ketamin & Indutor anestésico \\
\hline Insulina & $\begin{array}{c}\text { Insulina regular, } \\
\text { rápida ou simples }\end{array}$ & $\begin{array}{c}\text { Tratamento de pacientes } \\
\text { com diabetes melito que } \\
\text { necessitam de insulina } \\
\text { para manutenção da } \\
\text { homeostase de glicose }\end{array}$ \\
\hline
\end{tabular}

Fonte: Brasi $1^{17}$.

Em uma revisão integrativa da literatura realizada por Azevedo et al. ${ }^{7}$, constatou-se a inexistência do uso de antibióticos por via $\mathrm{SC}$ em pacientes sob cuidados paliativos. Nesse sentido, destaca-se a necessidade de investigaçóes que fortaleçam a prática cotidiana da enfermagem nos cuidados paliativos em assistência domiciliar, atendimento ambulatorial ou internação hospitalar, visto que os benefícios reais com a utilização da via parenteral são evidentes.

Entre os medicamentos incompatíveis com a via subcutânea estão: diazepam, diclofenaco, fenitoína, clorpromazina (provocam necrose tecidual) e eletrólitos não diluídos ${ }^{5,11}$.

Relativo ao volume de fluidos suportados pela via subcutânea, Viegas ${ }^{8}$ explica que o espaço subcutâneo permite a administração de volumes de 1.000 a 1.500 $\mathrm{ml} \mathrm{em} 24 \mathrm{~h}$.

No estudo de Pontalti et al. ${ }^{5}$, afirmaram que o volume a ser infundido continuamente pode ser solução salina a $0,9 \%$ ou glicose a $5 \%$. É tolerado o volume diário de 1.000 a $3.000 \mathrm{ml} /$ dia. Para outros autores, a variação é de 500-1.000 $\mathrm{ml}$ por dia, chegando até $3.000 \mathrm{ml} \mathrm{em}$ dois sítios distintos. $\mathrm{O}$ tempo adequado de infusão para $500 \mathrm{ml}$ é de 8-12 horas, ou então $500 \mathrm{ml}$ em 1-2 horas, até três vezes ao dia. Portanto, concluiu-se que não existe um consenso na literatura, e sim controvérsias que somente pesquisas experimentais poderão sanar.

Já na revisão de Takaki e Klein ${ }^{6}$, evidenciou-se que o volume máximo de infusão de fluidos diária não deve ultrapassar $3.000 \mathrm{ml}$. No estudo de Arriera et al. ${ }^{3}$, destaca-se que, durante 24 horas, o volume de infusáo de 
fluidos pode variar de 500 a $2.000 \mathrm{ml}$ de solução a ser infundida (glicose a $5 \%$ ou soro fisiológico a $0,9 \%$ ).

A hipodermóclise apresenta limitaçóes nas situaçóes em que se deseja uma velocidade de infusão rápida e reposição com alto volume de fluidos. $\mathrm{O}$ volume diário recomendado é de $2.000 \mathrm{ml} \mathrm{em} 24$ horas $(1.000 \mathrm{ml}$ por sítio) $)^{12,18}$.

\section{Conclusões}

A via subcutânea é um recurso importante para os pacientes em cuidado paliativo, idosos e em demais situaçóes clínicas, proporcionando qualidade de vida a esses doentes. No entanto, é pouco discutida, pouco conhecida e, consequentemente, menos utilizada. É essencial que as instituiçóes de ensino incluam esse tema nas grades curriculares, para que o enfermeiro adquira conhecimento e busque aprofundá-lo.

Desse modo, a necessidade pelo conhecimento sobre esse assunto se dá pelo controle sintomático ser um componente essencial no cuidado à pessoa em fim de vida. Os ganhos em saúde com o recurso a essa via são notórios. Assim, são necessárias pesquisas para consolidar o uso da hipodermóclise no Brasil, considerando que há carência nos estudos.

\section{Referências}

1. Pombo D. A via subcutânea para hidratação e administraçáo de terapêutica na pessoa com patologia crónica e/ou paliativa [Dissertação de Mestrado em Enfermagem MédicoCirúrgica]. Setúbal: Escola Superior de Saúde do Instituto Politécnico de Setúbal; 2012.

2. Cunha AMB. Nutriçấo e bioética nos cuidados paliativos [Monografia]. Brasília: Universidade de Brasília; 2013.

3. Arrieira IC, Thofern MB, Ceolin T, Heck RM, Zillmer JGV, Schwartz E. Infusão subcutânea como alternativa em cuidados paliativos. Ciência, Cuidado e Saúde. 2008;7(2):1-3.

4. Justino ET, Tuoto FS, Kalinke LP, Mantovani MF. Hipodermóclise em pacientes oncológicos sob cuidados paliativos. Cogitare Enfermagem. 2013;18(1):84-9.

5. Pontalti G, Rodrigues ESA, Firmino F, Fabris M, Stein MR, Longaray VK. Via subcutânea: segunda opção em cuidados paliativos. Subcutaneous route: second option in palliative care. Revista HCPA. 2012;32(2):199-207.

6. Takaki CYI, Klein GFS. Hipodermóclise: o conhecimento do enfermeiro em unidade de internação. ConScientiae Saúde. 2010;9(3):486-96.

7. Azevedo EF, Barbosa LA, Cassiani SHDB. Administração de antibióticos por via subcutânea: uma revisão integrativa da literatura. Acta Paul Enferm. 2012;25(5):817-22.

8. Viegas M. Via Subcutânea: uma nova alternativa. $1^{\circ}$ Prêmio de Comunicaçáo Livre das Ia Jornadas de Enfermagem Médico-Cirúrgica do CHBA; Lagos; 2011.

9. Lopes JMM. Utilização da via subcutânea no doente em cuidados paliativos [Dissertação de Mestrado em Cuidados Paliativos]. Castelo Branco: Instituto Politécnico de Castelo Branco; 2014.

10. Nascimento ES, Teixeira VMMN. Redação técnico-científica e pesquisa bibliográfica: algumas reflexôes. Enfermagem Revista. 2012;15(2):213-28.

11. D'aquino M, Souza RM. Hipodermóclise ou via subcutânea. Revista do Hospital Universitário Pedro Ernesto. 2012;11(2).

12. Girondi JBR, Waterkemper R. A utilização da via subcutânea como alternativa para o tratamento medicamentoso e hidratação do paciente com câncer. Revista Mineira de Enfermagem. 2005;9(4):348-54.

13. Bicho VSP. Hipodermóclise em internamento de agudos [Dissertação de Mestrado em Cuidados Paliativos]. Castelo Branco: Instituto Politécnico de Castelo Branco; 2014.

14. Moreira LML. Hipodermóclise: uma forma de dignificar a vida na prestação de cuidados de saúde no domicílio [Mestrado]. Lisboa: Universidade de Lisboa; 2010.

15. Soriano Fernadez H, Garcia LR, Escribano DM, Castillo BR, Moreno EC, Garcia EP. Utilización de la Vía Subcutánea en Atención Primaria. Rev Clin Med Fam. 2009;2(8):426-33.

16. Oliveira SS, Sousa JA, Silva SdF, Jeremias WJ. Infusão subcutânea de analgésicos em pacientes oncológicos sob cuidados paliativos: uma revisão de literatura. e-Scientia. 2014;7(1).

17. Brasil. Ministério da Saúde. Instituto Nacional de Câncer. Terapia subcutânea no câncer avançado. Rio de Janeiro. 2009:31-4.

18. Ministério da Saúde. Instituto Nacional de Câncer. Cuidados Paliativos Oncológicos: controle da dor. Rio de Janeiro: INCA. 2001;328. 